\title{
Optimizing the time of doxil injection to increase the drug retention in transplanted murine mammary tumors
}

This article was published in the following Dove Press journal:

International Journal of Nanomedicine

25 March 2010

Number of times this article has been viewed

\section{Shaojin You \\ Lian Zuo \\ Wei Li}

Experimental Cancer Therapeutic Laboratory and Histopathology Core, Atlanta Research and Educational Foundation (I5IF), Atlanta VA Medical Center, Decatur, GA, USA
Correspondence: Shaojin You Atlanta Research and Educational Foundation, Atlanta VA Medical Center (I5IF), I670 Clairmont Road, Decatur, GA 30033, USA

$\mathrm{Tel}+\mid 40432$ I 6III ext. 25I6

Fax + I 404235306 I

Email shaojin.you@va.gov
Abstract: Sex hormonal milieus during the female fertility cycle modulate the tumor vascular permeability of breast cancer. It has been proposed that the liposomal formulated doxorubicin (ie, Doxil), given at the menstrual/estrous stage with the predicted highest tumor vascular permeability, allows significantly increased drug retention in the breast tumor. In the current study, syngeneic murine 4T1 mammary tumors were established on the backs of female $\mathrm{BALB} / \mathrm{c}$ mice and Doxil was administered at particular mouse estrous cycle stages. The results indicated that Doxil administration during certain times in the mouse estrous cycle was crucial for drug retention in 4T1 tumor tissues. Significantly higher drug concentrations were detected in the tumor tissues when Doxil was administered during the diestrus stage, as compared to when the drug injection was given at all other estrous stages. Our study also showed that the tumor-bearing mice exhibited nearly normal rhythmicity of the estrous cycle post drug injection, indicating the feasibility of continual injection of Doxil at the same estrous cycle stage. By using 4T1 cells cultured in vitro, we showed that progesterone (P4) significantly inhibited cell proliferation and the production of six tumor-derived cytokines, eg, sTNF-RI, CXCL-16, GM-CSF, MIP-1 $\alpha$, MIP-1 $\gamma$, and Flt3-L. Some of these factors have been shown to be vascular modulators in diverse tissues. In this report, we demonstrated that the concentration of P4 in the plasma and/or estrous cycle stage of 4T1 tumor-bearing mice can be used to select the best time for administrating the liposomal anticancer drugs.

Keywords: progesterone, menstrual cycle, mouse mammary tumor, Doxil, breast cancer therapy

\section{Introduction}

Recent advances in cancer therapy have utilized nanovectors to deliver cytotoxic drugs in an attempt to reduce drug-related side effects, extend the serum half life, and improve cancer therapeutic efficiency. Breast cancer is a disease that usually features leaky blood vessels with high permeability. The defective vasculature architecture, created as a result of the rapid vascularization that is necessary to serve fast-growing cancers, coupled with poor lymphatic drainage, allows an enhanced permeation and retention (EPR) of nanoformulated drugs or nanodrugs. ${ }^{1,2}$ It is obvious that the vascular permeability of tumor tissues directly correlates with the nanodrug retention in vivo. This feature can be utilized for enhancing cancer therapeutic efficacy. Because the vascular mediator plays an important role in modulation of tumor vascular permeability, administration of the vascular antagonists can significantly suppress the EPR effect in tumors. ${ }^{3}$ Rolipram, an anti-inflammatory drug, was incorporated into a nanoparticle and tested in a rat model of inflammatory bowel disease. ${ }^{4}$ The rats that 
received the nanoformulated rolipram demonstrated a better response based on the myleoperoxide activities as compared to free rolipram.

The female fertility cycle of humans is characterized by rhythmic fluctuations of hypothalamic, hypophyseal, adrenal, and ovarian hormones. The dynamic balance among prolactin, follicle-stimulating hormone (FSH), luteinizing hormone (LH), cortisol, estrogen, and progesterone modulates cellular proliferation in many organs, such as ovary, uterus, and breast. The rhythmic fluctuation of sex hormones during the menstrual cycle also controls breast cancer angiogenesis and/or tumor vascular permeability. We previously proposed that this natural exiting mechanism could be used to increase the drug retention of nanoformulated anticancer drugs in breast cancer tissue. ${ }^{5}$ It was hypothesized that nanodrugs (ie, Doxil; Centocor Ortho Biotech Inc., Horsham, PA, USA) given at the menstrual stage with the predicted highest cancer vascular permeability would allow significantly increased drug retention in breast cancer tissue and, subsequently, result in the maximal cancer growth control. On the contrary, if nanodrugs are given at the menstrual stage with the predicted lowest cancer vascular permeability, drug retention within the cancer would be lower. In the current study, we show that Doxil administration can be optimized to achieve the highest drug retention in tumors by monitoring the host estrous cycle.

\section{Materials and methods}

\section{Cell line and cell culture}

The murine 4T1 mammary tumor cells obtained from the American Type Culture Collection (ATCC) were cultured and maintained at $37^{\circ} \mathrm{C}$ in a humidified incubator with $5 \% \mathrm{CO}_{2}$. The cell culture medium consisted of Dulbecco's modified Eagle's medium (DMEM; Sigma, St. Louis, MO, USA), 10\% fetal bovine serum (Gibco, Carlsbad, CA, USA), 2 mM Lglutamine, $100 \mathrm{U} / \mathrm{mL}$ penicillin, and $100 \mu \mathrm{g} / \mathrm{mL}$ streptomycin (Gibco, Carlsbad, CA, USA).

\section{Mice}

Female virgin BALB/c mice (4-5 weeks old) were obtained from Charles River (Portage, MI) and housed with food and water provided ad libitum under a 12-hour lights on, 12-hour lights off cycle. After two months (12-13 weeks of age), vaginal smears were performed daily using sterile saline washings and cell smears were stained with Diff Quick staining solution (JT Baker, NJ, USA). Stages of the mouse estrous cycle were identified by cytological evaluation of vaginal smears as described previously.,

\section{TI tumor cell implantation and Doxil injection}

A single cell suspension of 4T1 tumor cells was prepared at $2 \times 10^{5}$ cells $/ \mathrm{mL}$ in basic DMEM cell culture medium. The cell suspension ( $50 \mu \mathrm{L} /$ mouse) was inoculated by subcutaneous injection in the back of two groups of female cycling BALB/c mice. Tumor size (TS) was measured daily using a caliper (length $\times$ width $\times$ height). When tumors reached an average size of $\sim 1500 \mathrm{~mm}^{3}$, the mice were assigned to two experimental groups. One group of nine mice was treated with an intravenous injection of Doxil (pegylated liposomal doxorubicin; Ortho Biotech) at $9 \mathrm{mg} / \mathrm{kg}$ of body weight and euthanized 24 hours later. Tumor tissues were harvested and snap frozen in liquid nitrogen, and then stored at $-80^{\circ} \mathrm{C}$. A second group of 20 tumor-bearing mice was further divided into two groups of 10 mice each. One group received an intravenous injection of Doxil (as described above) and the second group (control) was injected with saline. Tumor size and estrous cycle stage were monitored daily for two weeks and the mice were euthanized at the end of this period. Tumor tissues were harvested, fixed in 10\% buffered formalin, and embedded in paraffin.

\section{Determination of doxorubicin (Dox) concentration in the 4TI tumor tissues}

Extracts of dissected frozen tumor tissues were prepared by extraction with chloroform/isopropanol $(1: 1)^{8,9}$ and used to determine doxorubicin concentration according to the method of Charrois. ${ }^{10}$ Briefly, tissues were homogenized, extracted with chloroform/isopropanol (1:1), and centrifuged at $15,000 \mathrm{xg}$ for $20 \mathrm{~min}$. The upper aqueous layer was discarded and the lower organic layer containing the lipophilic Dox was used to determine Dox concentration. A second extraction of each tissue extract was prepared by adding $200 \mu \mathrm{L}$ of the chloroform/isopropanol layer to a 2-mL microcentrifuge tube containing $100 \mu \mathrm{L} 10 \%$ Triton $\mathrm{X}-100,200 \mu \mathrm{L}$ water, and $1,500 \mu \mathrm{L}$ acidified isopropanol $(0.75 \mathrm{~N} \mathrm{HCl})$. The tubes were mixed thoroughly and Dox and its metabolites were extracted overnight at $-20^{\circ} \mathrm{C}$. The tubes were warmed to room temperature, vortexed for $5 \mathrm{~min}$, and centrifuged at 15,000xg for $20 \mathrm{~min}$. Dox in the lower layer was quantified fluorometrically $\left(\lambda_{\text {excitation }} 470 \mathrm{~nm}\right.$ and $\lambda_{\text {emission }} 590 \mathrm{~nm}$ ). To correct for nonspecific background fluorescence, serum samples derived from drug-free mice were analyzed as controls. The data are represented as Dox micro equivalents/per $\mathrm{mL}$ tissue extraction (mean \pm standard deviation [SD] of triplicate aliquots). 


\section{Immunohistochemistry}

Multiple sections $(5-\mu \mathrm{m})$ were cut from each tumor tissue paraffin block and mounted on positively charged glass slides (Fisher Scientific, Pittsburgh, PA, USA). After deparaffinization and hydration, the tissue slides were placed in a glass container filled with citrate buffer $(10 \mathrm{mM}$ sodium citrate, $0.05 \%$ Tween 20, pH6.0) and heated in a microwave for 15 minutes for antigen retrieval. Endogenous peroxidase activity was blocked by incubating the slides in phosphate-buffered saline (PBS) containing $3 \% \mathrm{H}_{2} \mathrm{O}_{2}$ for 15 minutes. Slides were then incubated in 5\% normal horse serum for one hour at room temperature. Primary rabbit polyclonal antibody against nuclear progesterone receptor (PR; diluted 1:400) or goat polyclonal antibody against membrane-associated progesterone receptor alpha (mPR $\alpha$; diluted 1:200) (both from Santa Cruz Biotechnology, Santa Cruz, CA, USA) was applied to slides followed by incubation overnight at $4^{\circ} \mathrm{C}$. Biotinylated anti-rabbit or anti-goat antibodies (dilutions 1:300; ImmPress Reagent Kit, Vector, Burlingame, CA, USA) were applied and the slides were incubated for 30 minutes at room temperature. Between each step of the immunostains, slides were washed twice $(5 \mathrm{~min} / \mathrm{each}$ ) in PBS buffer ( $\mathrm{pH}$ 7.2). The color was developed by DAB substrate (Vector) and the sections were counterstained with hematoxylin. The immunostained slides were evaluated and photographed using a Nikon microscope (MICROPHOT-SA; Nikon, Tokyo, Japan) with a 40× objective and an Olympus digital camera (DP71; Olympus, Tokyo Japan).

\section{Protein microarray assays for profiling the expression of tumor derived cytokines}

The 4T1 tumor cells were cultured and treated with progesterone (P4; Sigma-Aldrich) at 0, $15 \mathrm{ng} / \mathrm{mL}, 30 \mathrm{ng} / \mathrm{mL}$, and $60 \mathrm{ng} / \mathrm{mL}$ for 24 hours. Total cell lysates were prepared using $500 \mu \mathrm{L}$ of ice-cold cell lysis buffer, $\mathrm{pH}$ 7.4 (50 mM HEPES, $5 \mathrm{mM}$ EDTA, $50 \mathrm{mM} \mathrm{NaCl}, 1 \%$ Triton X-100, $10 \mu \mathrm{g} / \mathrm{mL}$ aprotinin, $1 \mathrm{mM}$ phenylmethylsulfonyl fluoride, $10 \mu \mathrm{g} / \mathrm{mL}$ leupeptin, $50 \mathrm{mM}$ sodium fluoride, $1 \mathrm{mM}$ sodium orthovanadate, and $10 \mathrm{mM}$ sodium pyrophosphate). The protein expression profiling analyses were then conducted using a mouse cytokine antibody microarray (RayBiotech, Inc., Norcross, GA, USA). The analysis was done twice.

\section{Cell proliferation assay}

The XTT cell proliferation assay was performed according to the manufacturer's protocol (Cayman Chemicals, Ann
Arbor, MI, USA). Briefly, 4T1 cells were seeded in a 96-well plate $\left(10^{4}-10^{5}\right.$ cells $/ 100 \mu \mathrm{L} /$ well $)$ with $\mathrm{P} 4$ at $0,15 \mathrm{ng} / \mathrm{mL}$, $30 \mathrm{ng} / \mathrm{mL}$, and $60 \mathrm{ng} / \mathrm{mL}$ and incubated for 24 hours at $37^{\circ} \mathrm{C}$. Reconstituted XTT mixture $(10 \mu \mathrm{L})$ was added to each well and the cells were incubated for 2 hours at $37^{\circ} \mathrm{C}$. Absorbance at $450 \mathrm{~nm}$ was measured using a microplate reader.

\section{Progesterone treatment induced cell death in vitro}

The 4T1 cells were seeded in $35 \mathrm{~mm}$ Petri dishes at concentration of $2 \times 10^{5}$ cells $/ \mathrm{ml}$ and cultured for 1-2 days. Growth medium was replaced with medium containing P4 $(0,15 \mathrm{ng} / \mathrm{mL}$, $30 \mathrm{ng} / \mathrm{mL}$, or $60 \mathrm{ng} / \mathrm{mL}$ ) when the cultures were $70 \%$ confluent and the cultures were incubated for an additional 24 hours. Cells were photographed using an inverted Olympus microscope with a $10 \times$ objective and a digital camera.

\section{Statistics}

For all statistical analyses, a significance level of $P<0.05$ was employed. A two-sided Student's $t$-test was used to test the differences between the means of control and drugtreated groups.

\section{Results}

The time of Doxil administration during mouse estrous cycle and its effects

\section{on drug retention in $4 \mathrm{TI}$ tumors}

To test our hypothesis, we conducted two animal experiments. For each experiment, subcutaneous murine 4T1 mammary tumors were established on the backs of female BALB/c mice. In the first group of mice, Doxil was injected when the 4T1 tumors were $~ 1,500 \mathrm{~mm}^{3}$ and the tumor-bearing mice were sacrificed 24 hours later. Tumor tissues were harvested and Dox concentration within each tumor was measured. As shown in Figure 1A, Dox concentrations in the 4T1 tumors were significantly higher $(7.74 \mu$ equivalents $/ \mathrm{mL}, \mathrm{n}=3)$ when the drug was injected during the diestrus stage, as compared to those tumors when the drug was injected in all other estrous stages $(1.38 \mu$ equivalents $/ \mathrm{mL}, \mathrm{n}=6 ; P=0.01)$. These data suggest that the diestrus stage may represent the best time for Doxil injection in 4T1 tumor-bearing mice (Figure 1B).

\section{Doxil administration and its effects on the growth of 4TI tumors and estrous cycle rhythms of tumor-bearing mice}

In the second group of mice, estrous cycle and tumor sizes were monitored daily throughout the experiment, prior to 
A

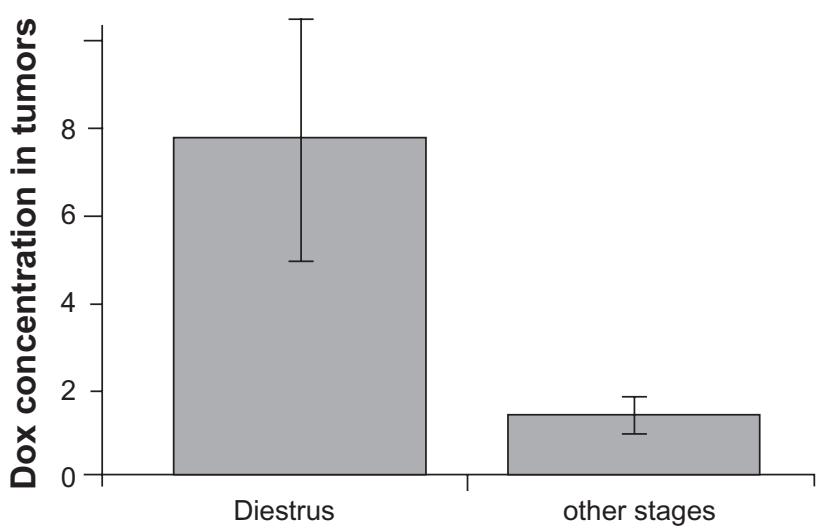

Time of Doxil injection

B

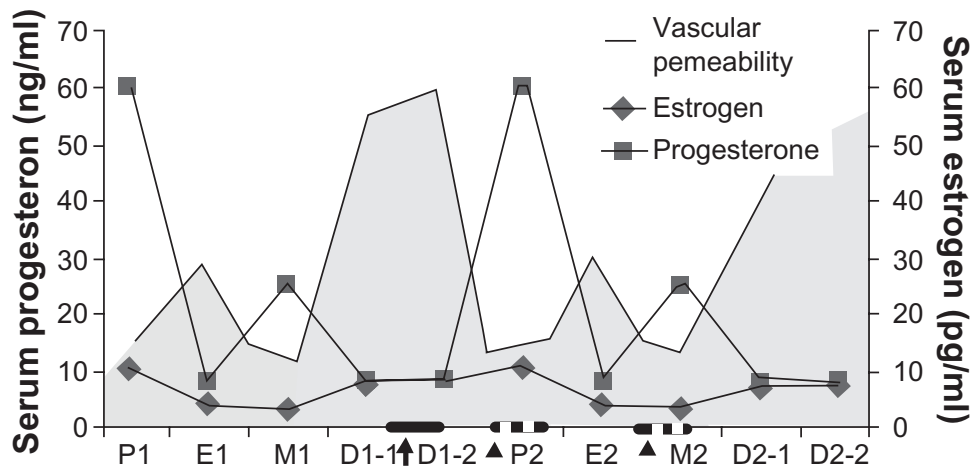

Estrous cycle stages of mouse

Figure I The time of Doxil administration during mouse estrous cycle and its effects on drug retention in 4TI tumors. A) The Dox concentrations in 4TI tumors when Doxil is injected during diestrus stage or other estrous stages. B) The dynamic changes of serum progesterone and estrogen levels during the estrous cycle. The concentrations of P4 and E2 in mice were previously published. ${ }^{13}$ The best time for Doxil injection is indicated by the black arrow and bar.The worst times for Doxil injection are indicated by small triangles and dotted bars.

and post-Doxil administration. As shown in Figures 2A and 2B, 4T1 tumor implantation and Doxil injection has little effect on the length of the estrous cycle and individual estrous stages. The length of diestrus appears to be extended slightly from an average of 1.8 days to 2.5 days by Doxil injection. The difference, however, is not statistically significant $(P>0.05)$. Figure $2 \mathrm{C}$ shows the sensitivity of implanted 4T1 tumors to Doxil treatment. Tumor size measurements were started in the second group of mice when implanted tumors were palpable (day 1). Tumors grew to the target size $\left(1500 \mathrm{~mm}^{3}\right)$ in about 13 days at which point mice were treated with either Doxil or saline. Average tumor size in the Doxil group decreased from $1,504 \mathrm{~mm}^{3}$ to about $456 \mathrm{~mm}^{3}$ by day 28 . In contrast, tumors in the control group continued to grow to over $2000 \mathrm{~mm}^{3}$ by day 17 . Tumor size was estimated for some mice due to tumor ulceration and the control mice were sacrificed due to poor physiological condition.

\section{Expression of sex hormone receptors in 4TI tumors}

It is well known that $4 \mathrm{~T} 1$ tumors are negative for $\mathrm{ER} \alpha$ and nonresponsive to current endocrine therapeutics, ${ }^{11}$ which raises a question: How do 4T1 tumors respond to the rhythmic fluctuations in sex hormones and regulate tumor growth and angiogenesis during the estrous cycle? In this study, we demonstrate the expression of nuclear PR and $\mathrm{mPR} \alpha$ in 4T1 tumors. As shown in Figure 3, strong positive staining for PR is seen in the nuclei of most 4T1 tumor cells (white arrows in Figure 3A), while only weak positive signals for $\mathrm{mPR} \alpha$ are observed in the cytoplasm of tumor cells (yellow arrows in Figure 3B).

\section{The effect of progesterone on the expression of tumor-derived cytokines}

Sex hormones are rhythmically changing during the mouse estrous cycle. Plasma levels of estradiol (E2) fluctuate 
A

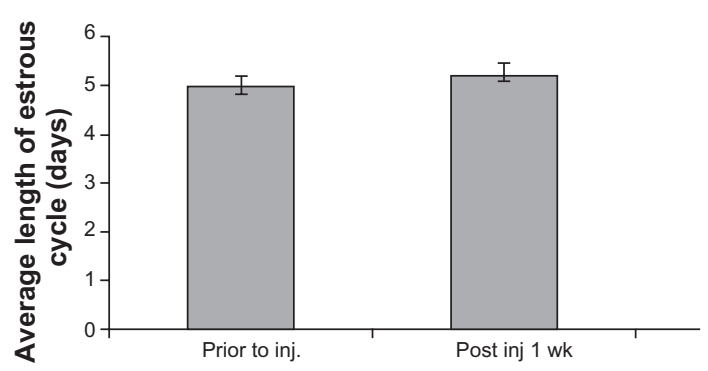

C
B

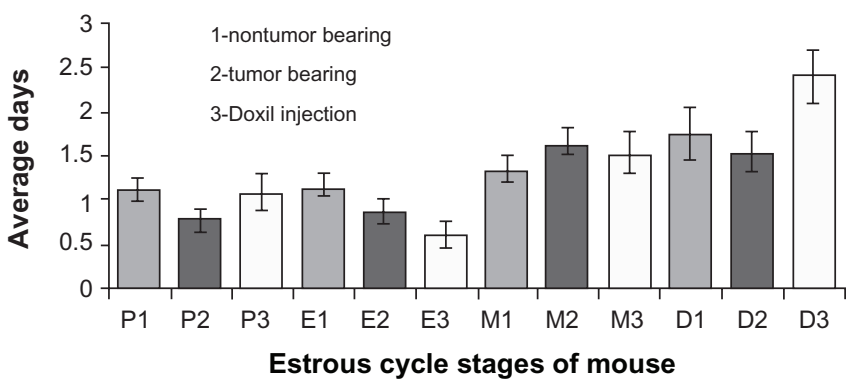

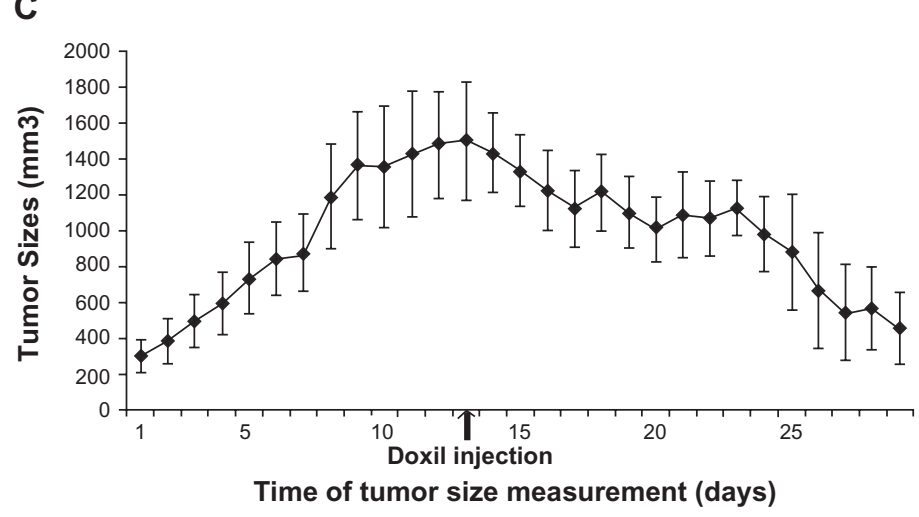

Figure 2 Doxil administration and its effects on the growth of 4TI tumors and estrous cycle of tumor-bearing mice. A) Length of estrous cycles that occur before and after Doxil injection. B) Length of estrous cycle stages in control and tumor-bearing mice prior to and after Doxil administration. C) Effect of Doxil treatment on 4TI tumor size.

between 3.1 and $10.5 \mathrm{pg} / \mathrm{mL}$ during mouse estrous cycle, ${ }^{12}$ while plasma progesterone (P4) levels alternate between 8 and $60 \mathrm{ng} / \mathrm{mL}$. Diestrus in mice corresponds to the lowest plasma $\mathrm{P} 4$ concentration. ${ }^{13}$ To determine the potential effects of the dynamic P4 levels on tumor derived cytokine secretion, the conditioned medium was harvested from 4T1 cell culture dishes and submitted to protein expression profiling analysis using a mouse cytokine antibody microarray. As shown in Figure 4, sTNF-RI, CXCL-16, GM-CSF, MIP-3 $\alpha$, MIP-1 $\gamma$, and Flt3-L are decreased dramatically $(P<0.05)$. Surprisingly, vascular endothelial growth receptor and basic fibroblast growth factor do not change as compared to vehicle-treated controls (data not shown).

\section{The effects of P4 on cell proliferation and cell death}

We also investigated the effects of $\mathrm{P} 4$ on cell proliferation and cell death of $4 \mathrm{~T} 1$ tumor cells in vitro. As shown in Figure $5 \mathrm{~A}$, a $30 \%$ reduction in cell proliferation is observed when 4T1 cells are treated with $\mathrm{P} 4$, as compared to vehicletreated controls. In contrast, there is about a $40 \%$ increase in cell proliferation when the cells are treated by E2 as a positive control. We further evaluated the growth status of 4T1 cells after P4 treatment. The number of dead cells or detached cells increases dramatically when cells are treated with increasing doses of P4 for 24 hours (Figure 5B).

\section{Discussion}

The enhanced vascular permeability and drug retention (EPR) theory, developed by Maeda and colleagues, ${ }^{1}$ is fundamental for nanoformulated drug or nanodrug delivery. The EPR effects of nanodrugs depend upon the enhanced tumor angiogenesis, defective vascular architecture, impaired lymphatic drainage system, and increased production of vascular permeability mediators. It was proposed that the changes in breast cancer capillary permeability putatively respond to the sex hormone milieus during the menstrual cycle. ${ }^{7}$ According to our hypothesis, the best time for nanodrug administration is when the peak of serum drug concentration meets with the highest degree of tumor vascular permeability. On the contrary, the worst time for the administration is the converse; that is when the peak serum drug concentration meets with the lowest degree of tumor vascular permeability. We assumed that, if the dynamic changes of tumor vascular permeability during menstrual cycle are obvious, optimizing the time of nanodrug administration at proper menstrual cycle stage may 

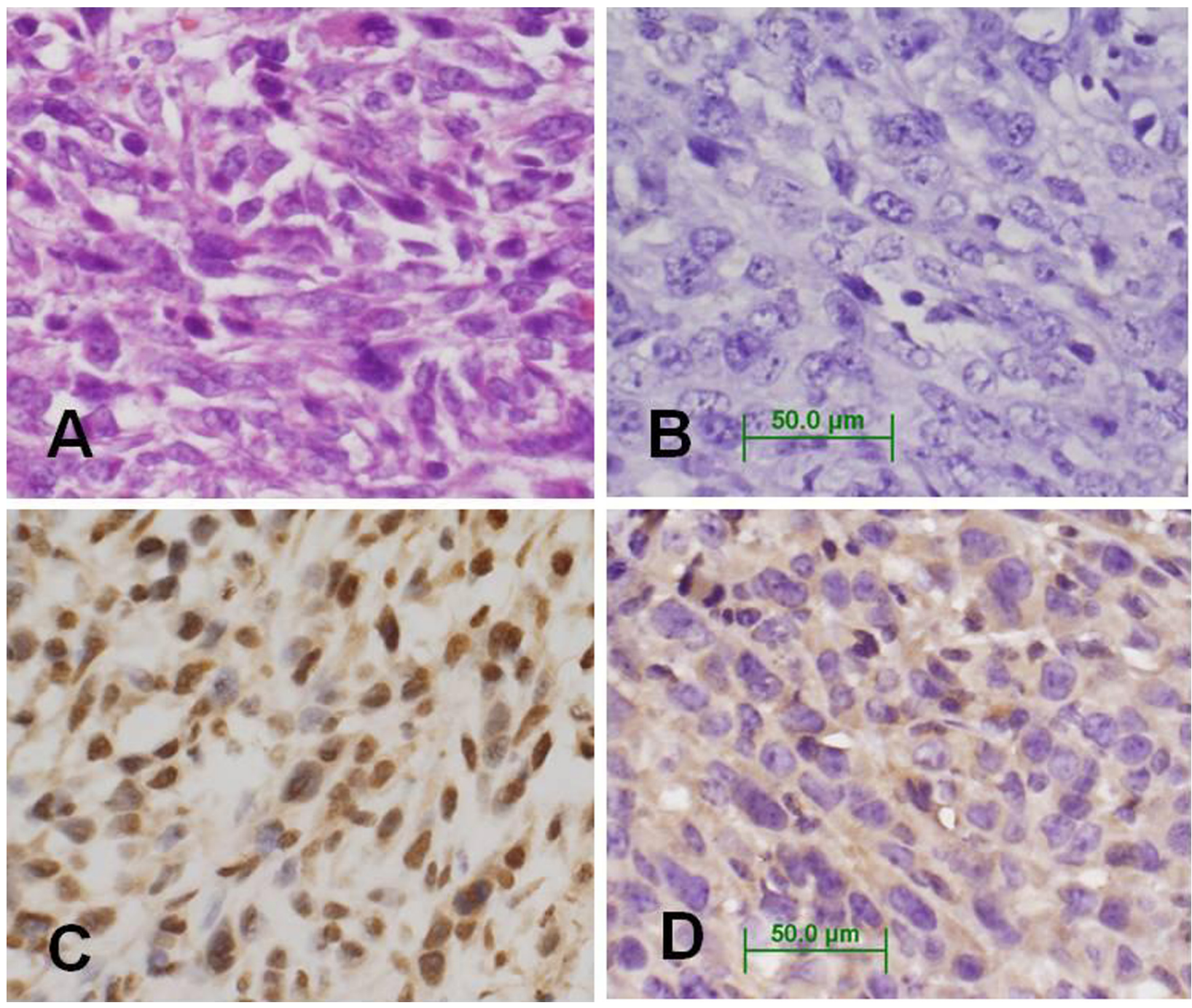

Figure 3 Immunohistochemical analysis of PR and mPR $\alpha$ protein expression in 4TI tumor tissues. A) 4TI tumor stained with $\mathrm{H}$ \& E. B) Negative control of 4TI tumor tissue stained without primary antibody. Magnification of all images is $400 \times$. C) $4 T I$ tumor tissue stained with anti-PR. D) $4 T I$ tumor tissue stained with anti-mPR $\alpha$. Abbreviations: $\mathrm{H}$ \& E, hematoxylin \& eosin; PR, progesterone receptor; 4TI, mouse mammary cell line.

become crucial to increase the drug retention in breast cancer. In this study, we first observed higher drug retention in 4T1 tumors when Doxil was injected during diestrus, indicating the best time for Doxil administration in this particular tumor/mouse model.

For the mouse model used, there are four estrous stages - diestrus ( $48-72$ hours, the longest estrous stage), proestrus (12-14 hours), estrus (8-10 hours), and medestrus (24-36 hours). Enveloping doxorubicin in liposomal vesicles significantly extends the drug $\mathrm{T}_{1 / 2}$ from a few hours to about 55 hours. ${ }^{14}$ If Doxil is injected during one of the four estrous stages, the $T_{1 / 2}$ of Doxil will cover two or three successive estrous cycle stages. For example, if Doxil is given at the diestrus stage, the $T_{1 / 2}$ of the drug may cover diestrus, proestrus, and estrus. The serum concentration of $\mathrm{P} 4$ during this period starts at a low level and rises to the highest before dropping again (Figure 1B). It is assumed that the low serum concentration of $\mathrm{P} 4$ at the time of drug administration may have great impact on the production of tumor derived cytokines and tumor vascular permeability and subsequently increase drug retention within tumors.

Conventional Dox is widely used for treatment of metastatic breast cancer (MBC). The potential mechanistic actions of Dox include the inhibition of DNA topoisomerase and helicases causing cell S phase arrest. ${ }^{15-18}$ Although Dox is a widely used anticancer drug in the clinic, it has a number of undesirable side effects such as cardiotoxicity, myelosuppression, nephrositis, intestinal mucositis, and hair loss, which result in a very narrow therapeutic window. Another frequent side effect for premenopausal breast cancer patients 


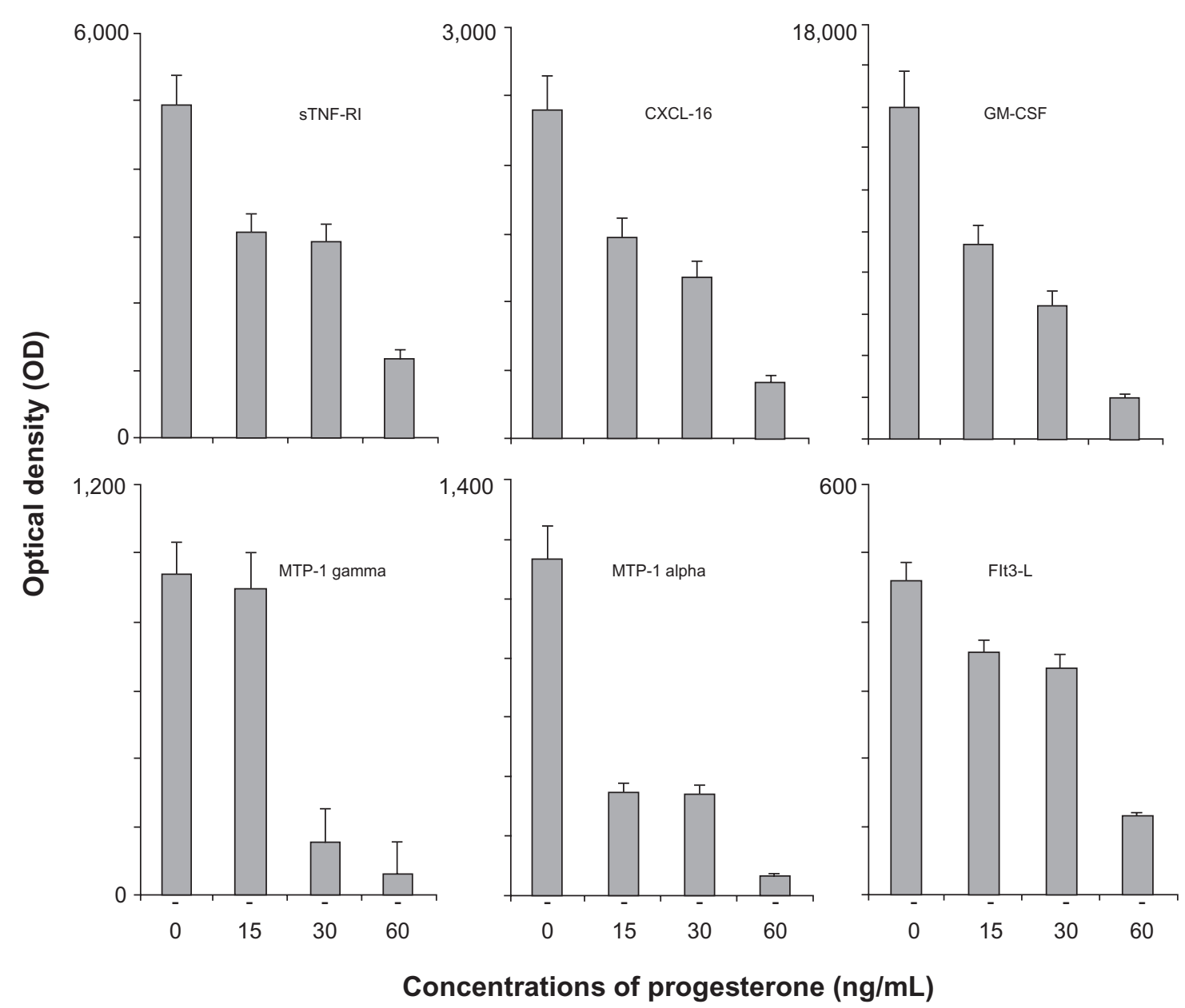

Figure 4 P4 treatment and cytokine expression in vitro. Scanned signal intensity of the hybridized protein array spots from a cytokine microarray assay of conditioned medium from 4TI mouse mammary cell cultures treated with progesterone for 24 hours. Each bar represents the average values from two hybridized spots of duplicate assays with subtraction of the baseline reading (baseline reading value $=100$ ).

treated with Dox is premature menopause or amenorrhea. Nearly all of the patients (96\%) aged between 40-49 years develop amenorrhea. ${ }^{19}$ This is a concern for the proposed chronotherapeutic strategy. This side effect, however, can be prevented if the drug is formulated in nanovectors. Pegylated liposomal doxorubicin (Doxil) has been used in the treatment of human cancer patients for more than ten years. ${ }^{20}$ Among dozens of clinical studies with liposomal Dox, none of them, so far, has reported amenorrhea as a common side effect of this drug. In this study, we provide a piece of preclinical evidence suggesting that administration of Doxil does not disrupt the rhythmicity of the mouse estrous cycle during at least two successive weeks, indicating the feasibility of continual injection of Doxil at the same estrous cycle stage.

Previous studies have shown that the bacterial endotoxin (lipopolysaccharide [LPS])-induced growth and metastasis of murine 4T1 tumors in experimental mice are associated with increased angiogenesis and vascular permeability. ${ }^{21,22}$ The growth of 4T1 tumors in mice induces a leukemoid reaction with profound granulocytosis coincident with the production of tumor-derived growth factors. In addition, 4T1 tumor cells in culture express mRNA transcripts for chemokines, including RANTES, MCP-1, and $\mathrm{KC} .{ }^{23}$ These data demonstrate that 4T1 tumor cells tend to produce a variety of inflammatory cytokines or chemokines to modulate the tumor cell growth and/or angiogenesis by paracrine or autocrine mechanisms. In this study, we demonstrated that progesterone inhibits the expression of numerous tumor-derived cytokines in vitro, such as sTNF-RI, CXCL-16, GM-CSF, MIP- $1 \alpha$, MIP- $1 \gamma$, and Flt3-L. Some of these tumor derived cytokines, such as MIP-1 $\alpha$, CXCL16, ${ }^{24}$ sTNF-RI, ${ }^{25}$ are important mediators for the immune and inflammatory reactions within diverse tissues. Others, such as GM-CSF, ${ }^{26}$ are novel mediators for neovascularization and vascular permeability. Our data support the hypothesis that tumor growth and angiogenesis in mice are modulated by the dynamic sex hormone milieus throughout the estrous cycle. 
A

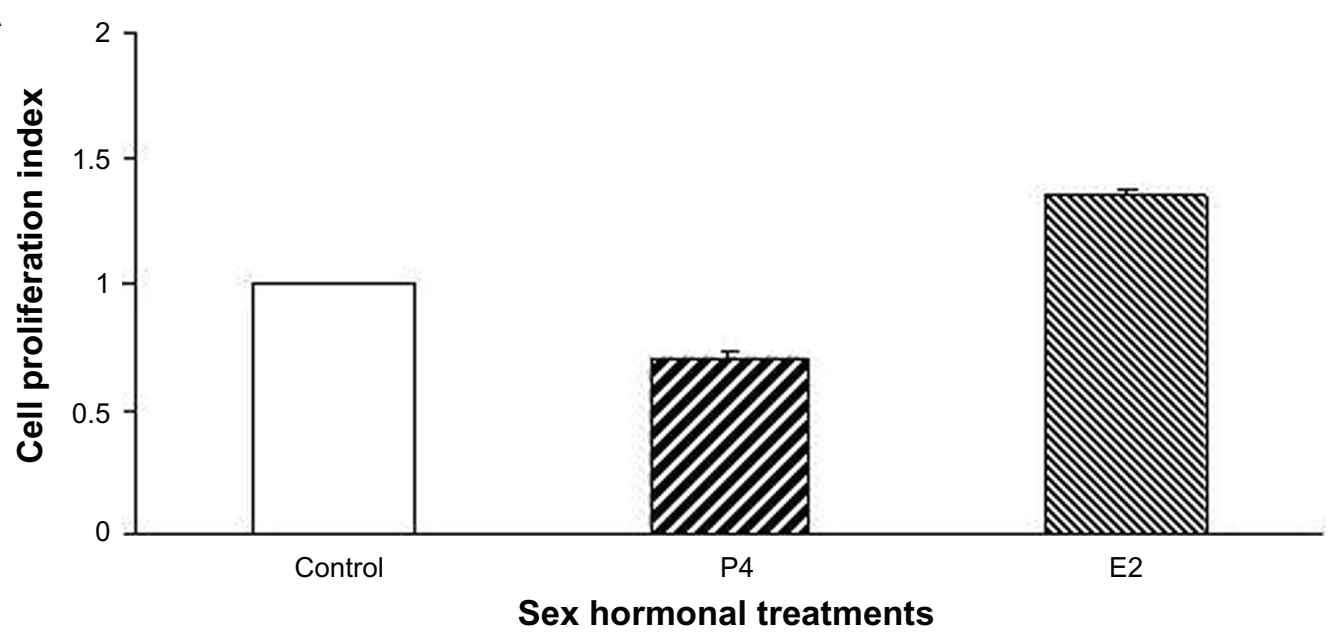

B
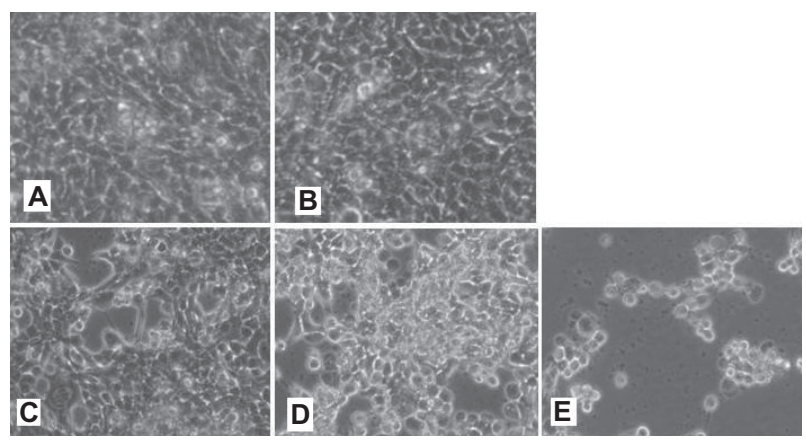

Figure 5 Effect of sex hormones on cell proliferation and cell death in vitro. A) Cell proliferation index measured for 4TI cultures treated with P4 or E2, compared to controls. The data were obtained from three experiments. B) Appearance of 4TI cultures treated with various doses of P4. A. control; B. E2; C. P4 I5 ng/ML; D. P4 30 ng/ML; $\mathrm{E}, \mathrm{P} 460 \mathrm{ng} / \mathrm{ml}$. Magnification of all images is $100 \times$.

Abbreviation: 4TI, mouse mammary cell lines.

\section{Conclusions}

The frequency of Doxil administration in the clinic is once every four weeks, which is approximately the same length as one human menstrual cycle. The proposed therapeutic strategy can therefore be easily adapted in human patients. In order to adapt this strategy to humans, the time of Doxil injection would need to be coordinated with the proper menstrual stage to correspond to the period of highest tumor vascular permeability. According to our hypothesis, the best time for Doxil administration may be when serum P4 is at the lowest concentration or the tumor cytokine production is at the highest point, both of which may correspond to the time of highest tumor vascular permeability. To further elucidate and confirm this proposed theory, experiments with larger groups of mice and diverse tumor cell models may be needed.

\section{Acknowledgments}

We greatly appreciate Dr Linda Gilbert (Endocrinology Laboratory, Atlanta Research and Educational Foundation,
Atlanta, GA) for her kind assistance in editing the manuscript. The authors declare that there is no conflict of interest that would prejudice the impartiality of this scientific report. Grant support was provided to Dr. You by the Department of Defense Breast Cancer Research Program Synergy Idea Award.

\section{References}

1. Matsumura Y, Maeda H. A new concept for macromolecular therapeutics in cancer chemotherapy: mechanism of tumoritropic accumulation of proteins and the antitumor agent smancs. Cancer Res. 1986;46: 6387-6392.

2. Sledge GW Jr, Miller KD. Exploiting the hallmarks of cancer: the future conquest of breast cancer. Eur J Cancer. 2003;39:1668-1675.

3. Wu J, Akaike T, Maeda H. Modulation of enhanced vascular permeability in tumors by a bradykinin antagonist, a cyclooxygenase inhibitor, and a nitric oxide scavenger. Cancer Res. 1998;58:159-165.

4. Lamprecht A, Ubrich N, Yamamoto H, et al. Biodegradable nanoparticles for targeted drug delivery in treatment of inflammatory bowel disease. J Pharmacol Exp Ther. 2001;299:775-781.

5. You $\mathrm{S}, \mathrm{Li} \mathrm{W}$. Administration of nanodrugs in proper menstrual stage for maximal drug retention in breast cancer. Med Hypotheses. 2008;71: 141-147.

6. You S, Li W, Kobayashi M, et al. Creation of a stable mammary tumor cell line that maintains fertility-cycle tumor biology of the parent tumor. In Vitro Cell Dev Biol Anim. 2004;40:187-195. 
7. Wood PA, Bove K, You S, et al. Cancer growth and spread are saltatory and phase-locked to the reproductive cycle through mediators of angiogenesis. Mol Cancer Ther. 2005;4:1065-1075.

8. Chu AC, Tsang SY, Lo EH, et al. Low density lipoprotein as a targeted carrier for doxorubicin in nude mice bearing human hepatoma HepG2 cells. Life Sci. 2001;70:591-601.

9. Lo EH, Ooi VE, Fung KP. Circumvention of multidrug resistance and reduction of cardiotoxicity of doxorubicin in vivo by coupling it with low density lipoprotein. Life Sci. 2002;72:677-687.

10. Charrois GJ, Allen TM. Rate of biodistribution of STEALTH liposomes to tumor and skin: influence of liposome diameter and implications for toxicity and therapeutic activity. Biochim Biophys Acta. 2003;1609:102-108.

11. Ford CE, Ekstrom EJ, Andersson T. Wnt-5a signaling restores tamoxifen sensitivity in estrogen receptor-negative breast cancer cells. Proc Natl Acad Sci US A. 2009;106:3919-3924.

12. Bergman MD, Schachter BS, Karelus K, et al. Up-regulation of the uterine estrogen receptor and its messenger ribonucleic acid during the mouse estrous cycle: the role of estradiol. Endocrinology. 1992;130:1923-1930.

13. Michael SD. Plasma prolactin and progesterone during the estrous cycle in the mouse. Proc Soc Exp Biol Med. 1976;153:254-257.

14. Rivera E. Liposomal anthracyclines in metastatic breast cancer: clinical update. Oncologist. 2003;8(Suppl 2):3-9.

15. Wahl AF, Donaldson KL, Mixan BJ, et al. Selective tumor sensitization to taxanes with the mAb-drug conjugate cBR96-doxorubicin. Int $J$ Cancer. 2001;93:590-600.

16. Sinha BK, Katki AG, Batist G, et al. Differential formation of hydroxyl radicals by adriamycin in sensitive and resistant $\mathrm{MCF}-7$ human breast tumor cells: implications for the mechanism of action. Biochemistry. 1987;26:3776-3781.

17. Bachur NR, Yu F, Johnson R, et al. Helicase inhibition by anthracycline anticancer agents. Mol Pharmacol. 1992;41:993-998.
18. Crespi MD, Ivanier SE, Genovese J, et al. Mitoxantrone affects topoisomerase activities in human breast cancer cells. Biochem Biophys Res Commun. 1986;136:521-528.

19. Hortobagyi GN, Buzdar AU, Marcus CE, et al. Immediate and long-term toxicity of adjuvant chemotherapy regimens containing doxorubicin in trials at M.D. Anderson Hospital and Tumor Institute. NCI Monogr. 1986;(1):105-109.

20. Muggia FM. Clinical efficacy and prospects for use of pegylated liposomal doxorubicin in the treatment of ovarian and breast cancers. Drugs. 1997;54(Suppl 4):22-29.

21. Harmey JH, Bucana CD, Lu W, et al. Lipopolysaccharide-induced metastatic growth is associated with increased angiogenesis, vascular permeability and tumor cell invasion. Int J Cancer. 2002;101: 415-422.

22. Pidgeon GP, Harmey JH, Kay E, et al. The role of endotoxin/lipopolysaccharide in surgically induced tumour growth in a murine model of metastatic disease. Br J Cancer. 1999;81:1311-1317.

23. DuPre SA, Redelman D, Hunter KW Jr. The mouse mammary carcinoma 4T1: characterization of the cellular landscape of primary tumours and metastatic tumour foci. Int J Exp Pathol. 2007;88: 351-360.

24. Tohyama M, Sayama K, Komatsuzawa H, et al. CXCL16 is a novel mediator of the innate immunity of epidermal keratinocytes. Int Immunol. 2007;19:1095-1102.

25. Jablonska E. Release of soluble IL-6 receptor (IL-6sR) in comparison with release of soluble TNF receptors (sTNF-Rs) by PMNs and WBC derived from breast cancer patients. Cancer Lett. 1997;119:79-85.

26. Horiuchi T, Weller PF. Expression of vascular endothelial growth factor by human eosinophils: upregulation by granulocyte macrophage colony-stimulating factor and interleukin-5. Am J Respir Cell Mol Biol. 1997; 17:70-77.
International Journal of Nanomedicine

\section{Publish your work in this journal}

The International Journal of Nanomedicine is an international, peerreviewed journal focusing on the application of nanotechnology in diagnostics, therapeutics, and drug delivery systems throughou the biomedical field. This journal is indexed on PubMed Central,

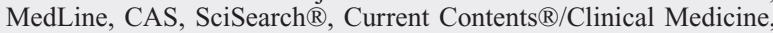

\section{Dovepress}

Journal Citation Reports/Science Edition, EMBase, Scopus and the Elsevier Bibliographic databases. The manuscript management system is completely online and includes a very quick and fair peer-review system, which is all easy to use. Visit http://www.dovepress.com/ testimonials.php to read real quotes from published authors 